\title{
Mycoplasma genitalium infection
}

\author{
Ameeta E. Singh BMBS MSc, Annie-Claude Labbé MD, Ulrick Auguste MD MSc
}

Cite as: CMAJ 2019 January 28;191:E103. doi: 10.1503/cmaj.180881

\section{1}

Mycoplasma genitalium infection is an emergent, sexually

transmitted infection (STI) that causes similar manifestations to gonorrhea and chlamydia

Infections caused by the bacteria Mycoplasma genitalium can be asymptomatic; however, symptoms can include dysuria and urethral discharge in men, and vaginal discharge in women. Complications in women include pelvic inflammatory disease, infertility, preterm birth and spontaneous abortion. ${ }^{1}$ Infections may occur in isolation or concurrently with other STIs.

\section{Mycoplasma genitalium infection is common worldwide}

The prevalence of infection caused by M. genitalium varies by population and geographic area. Canadian studies involving attendees at STI clinics have reported prevalences of $4.5 \%-5.3 \%$ in men and $3.2 \%-7.2 \%$ in women. ${ }^{2,3}$

\section{3}

\section{Routine testing for Mycoplasma genitalium infection is not} recommended

Testing is recommended in men with persistent or recurrent urethritis and in women with cervicitis or pelvic inflammatory disease despite empiric treatment, and when test results for gonorrhea and chlamydia are negative. ${ }^{4}$ Local laboratories should be consulted regarding specimen type and transport media, because access to nucleic acid amplification tests is variable across Canada. Antimicrobial resistance molecular testing is available at the National Microbiology Laboratory in Winnipeg.

Treatment options for Mycoplasma genitalium infection are limited by antimicrobial resistance

Azithromycin is recommended as the first-line agent for the treatment of uncomplicated M. genitalium infections (including in pregnancy). However, some Canadian studies have reported resistance rates of $47 \%$ to $58 \%$ for macrolides and $2 \%-20 \%$ for fluoroquinolones. ${ }^{2,3,4}$ Individuals who have not received previous empirical treatment for urethritis or cervicitis with single-dose azithromycin should receive a 5-day course of azithromycin. ${ }^{5}$ In treatment failure or with confirmed macrolide-resistant infection, moxifloxacin is recommended. ${ }^{5}$ Treatment failure with moxifloxacin is uncommon. Test of cure is recommended only in those with persistent symptoms after treatment. ${ }^{5}$

\section{Sexual partners should be treated with the same therapy as the index case}

Sexual partners should be treated regardless of the presence or absence of symptoms. ${ }^{5}$ They do not need to be tested before treatment. ${ }^{5}$

\section{References}

1. Jensen JS, Cusini M, Gomberg M, et al. Background review for the 2016 European guideline on Mycoplasma genitalium infections. J Eur Acad Dermatol Venereol 2016;30:1686-93.

2. Gesink D, Racey CS, Seah C, et al. Mycoplasma genitalium in Toronto, Ont: Estimates of prevalence and macrolide resistance. Can Fam Physician 2016;62:e96-101.

3. Gratrix J, Plitt S, Turnbull L, et al. Prevalence and antibiotic resistance of Mycoplasma genitalium among STI clinic attendees in Western Canada: a cross-sectional analysis. BMJ Open 2017;7:e016300.

4. Chernesky MA, Jang D, Martin I, et al. Canadian MG Study Group. Mycoplasma genitalium antibiotic resistance-mediating mutations in Canadian women with or without Chlamydia trachomatis Infection. Sex Transm Dis 2017;44:433-5.

5. Section 5-1: Canadian guidelines on sexually transmitted Infections - Management and treatment of specific infections Mycoplasma genitalium Infections. Ottawa: Public Health Agency of Canada; (modified 2018 July 27). Available: www. canada.ca/en/public-health/services/infectious-diseases/sexual -health-sexually-transmitted-infections/canadian-guidelines/ sexually-transmitted-infections/canadian-guidelines-sexually -transmitted-infections-49.html (accessed 2018 July 4).

\section{Competing interests: None declared.}

This article has been peer reviewed.

Affiliations: University of Alberta (Singh), Edmonton, Alta.; Université de Montréal (Labbé), Montréal, Que.; Public Health Agency of Canada (Auguste), Ottawa, Ont.

Correspondence to: Ameeta Singh, ameeta@ ualberta.ca

CMAJ invites submissions to "Five things to know about ..." Submit manuscripts online at http://mc. manuscriptcentral.com/cmaj 